\title{
Astronomy Communication and Popularization in the Brazilian Amazonia: The Astronomy Nucleus of the Federal University of Pará
}

\author{
Jocasta Caldas ${ }^{1}$, Rodrigo Rocha de França ${ }^{1}$, Luís Carlos Bassalo Crispino*1 \\ ${ }^{1}$ Faculdade de Física, Universidade Federal do Pará, 66075-110, Belém, PA, Brazil
}

Received on November 1, 2016. Revised on March 7, 2017. Accepted on March 12, 2017.

\begin{abstract}
The Astronomy Nucleus of the Federal University of Pará is a science center located in the Brazilian Amazonia, dedicated to spread knowledge on Astronomy to the general public. Over the last ten years, this science center has promoted several activities, including astronomical observations, demonstrations with industrially manufactured and low cost material equipment, seminars, workshops, among others. We describe and discuss the role of the Astronomy Nucleus and other science centers dedicated to Astronomy communication and popularization in the Brazilian Amazonia.

Keywords: Astronomy, Amazonia, Science Communication and Popularization.
\end{abstract}

\section{Introduction}

Astronomy research is widely developed all over the world. Several Astronomy research centers, including the ones hosted in universities and observatories, also promote significant educational and public outreach activities worldwide [1. We can mention, e. g., the public outreach programs of the National Aeronautics and Space Administration (NASA) [2], and of the Louisiana State University [3], both in the United States, as well as of the Carl Sagan Solar Observatory of the University of Sonora 4], in Mexico, and of the Observatoire de Haute Provence, in France [5], among others.

Astronomy outreach is also intensively promoted in planetariums worldwide, many of them listed in the International Planetarium Society website (IPS, http: //www.ips-planetarium.org). In Brazil, there are some traditional science centers devoted to Astronomy, but few located in the Amazonian region. The Brazilian planetariums are linked through a national association which organizes annual meetings and edits the magazine Planetaria (ABP, http://planetarios.org.br).

The Brazilian Amazonia includes 9 out of the 26 states of the Federative Republic of Brazil ${ }^{1}$ comprizing about half of the Brazilian territory, and has a population of about 15 million people [6]. In the whole Brazilian Amazonia, there is no formal course on Astronomy. The interest in the subject is stimulated by some outreach initiatives promoted by governmental institutions and by

\footnotetext{
*Endereço de correspondência: crispino@ufpa.br

${ }^{1}$ Brazilian Amazonia comprises the states of Acre, Amapá, Amazonas, Mato Grosso, Pará, Roraima, Rondônia, Tocantins and part of Maranhão state.
}

amateur astronomers groups. Although located far from the present developed centers in Brazil, Amazonia has gone through a wealthy and prosperous period, especially during the rubber cycle, between the second half of the nineteenth century and the beginning of the twentieth century. In that period, for instance, the Pará Museum was installed, turning out to be the first scientific institution in the Brazilian Amazonia [7. Astronomy has been part of the interest of the Amazonian population during that time. For instance, a practice of astronomical observations in Belém, the capital of the Brazilian state of Pará, has been announced in a local newspaper calling the local citizens to observe the great comet of 1882 , as well as the Moon, with the aid of a telescope mounted in a public park 8. As another example, we can mention the visit of the British astronomers A. C. D. Crommelin and C. R. Davidson to Amazonia, on their way to the city of Sobral, in the Northeast Brazilian state of Ceará, to perform the photographs that confirmed Einstein's Theory of General Relativity, taken during the May 29, 1919 total solar eclipse 9]. Some of Einstein's ideas related to General Relativity were publicized in Belém's press in that occasion, as well as how the local population observed and reacted to that eclipse 10,11.

Although the development of scientific diffusion on Astronomy (as well as on Science in general) in the Brazilian Amazonia region can be regarded as slow, when compared with wealthy regions of the globe, there exist important initiatives, figuring as significant learning aids and collaborating with the improvement of the local scientific literacy indices. As a major difficulty in this context, the number of educated people in Amazonia able and dedi- 
cated to publicize science is low compared with developed countries. As a way to overcome this issue, stands out the implementation of museums and science centers inside university environments. Such academic partnership contributes to increase the number of education professionals formed by the institutions, as well as collaborates with the maturation of the relationship between research, teaching and outreach sectors.

Among the institutional initiatives in the Brazilian Amazonia devoted to educational and public outreach stands out the Astronomy Nucleus (NASTRO, http: //www.nastro.ufpa.br) of the Federal University of Pará (UFPA, http://www.ufpa.br), located in the city of Belém. We present the activities developed by NASTRO along its ten years of existence. We also provide an overview of the main Brazilian national competitions on Astronomy and Astronautics, as well as a selection of amateur astronomers groups, other science centers and planetariums located in the Brazilian Amazonia that also perform educational activities in Astronomy.

\section{The Astronomy Nucleus of the Federal University of Pará}

The Astronomy Nucleus (NASTRO) is an educational and outreach science center of the Federal University of Pará (UFPA), which promotes public activities related to Astronomy and Astronautics, like astronomical observations, seminars, workshops, courses, classes using games and experiments, as well as exhibitions in the Brazilian Amazonia.

In 2005, an Astronomy Club has been created in UFPA by a group of undergraduate students and professors from the Physics Department, as part of the activities performed by the Demonstration's Laboratory (LABDEMON, http://www.labdemon.ufpa.br) 12, with the main initial aim to promote astronomical observations. The activities and the enthusiasm increased rapidly with time and in 2006 the Astronomy Club was transformed into the NASTRO. The Nucleus soon became a university project for popularization and diffusion of science. At present, NASTRO's team is composed by professors, students and technicians (cf. Fig. 1), mostly from the UFPA Institute of Exact and Natural Sciences and, more than an education and public outreach project, NASTRO is a reference science center devoted to Astronomy popularization in the Brazilian Amazonia.

The activities performed by NASTRO allow the community to interact with science. NASTRO encourages the study of these subjects to basic school students, as well as to the general public. The activities follow a playful view of teaching and learning, using not only professionally manufactured experiments (cf. Figs. 1s and 2s - supplemental files) but also low cost materials (cf. Fig. 2 - see also Fig. 3s - supplemental files). In Sec. 3 we give a detailed description of the main activities performed by NASTRO.

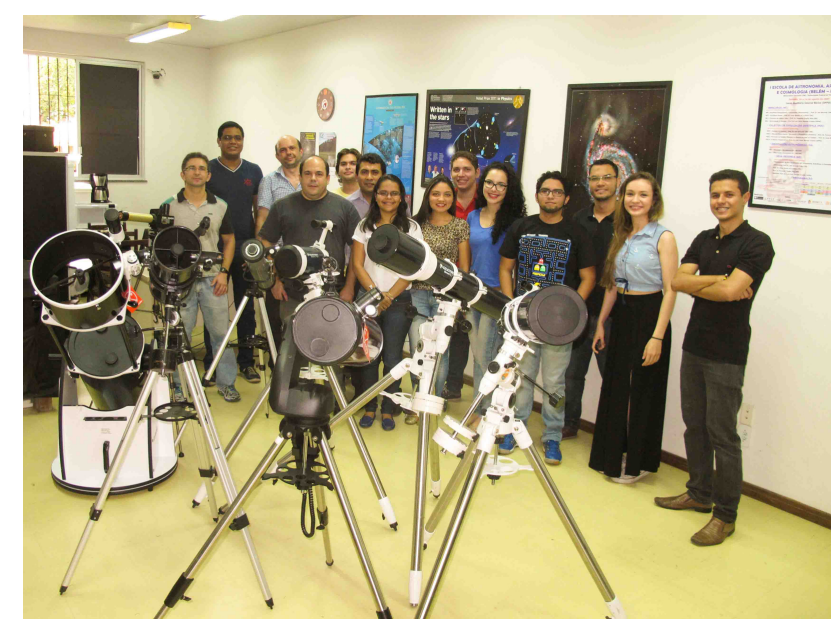

Figure 1: NASTRO's team at UFPA, standing behind the telescopes, in a photograph taken in November, 2015.

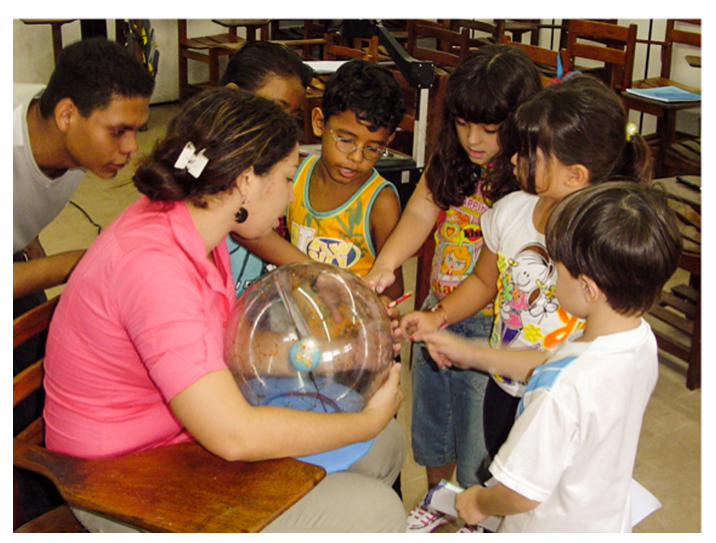

Figure 2: Children interacting with a representation of the celestial sphere built with low cost material during a NASTRO's class, in Belém, in January 2006.

\section{Activities Promoted by NASTRO}

NASTRO's goals include the dissemination of scientific knowledge to general public, providing seminars (cf. Fig. $4 \mathrm{~s}$ - supplemental files), courses, observations (cf. Fig. 3), participation in science fairs (cf. Fig. 5s - supplemental files), among other activities. Indeed, most of the astronomical events visible in Belém and other cities in Pará state are observed and publicized by NASTRO's team.

The activities of NASTRO are both internal, held inside UFPA, and external, developed in parks, schools and other places, as touristic points in the city of Belém, as well as in islands and other cities in Pará state. The internal activities include presentations for groups using interactive resources, meetings, and astronomical observations in the UFPA campus. Furthermore, NASTRO also offers preparation for the Brazilian Olympiad of Astronomy and Astronautics, and for the Brazilian Exhibition of Rockets. As external activities, NASTRO promotes itinerant exhibitions, observations of astronomical phenomena, as well as seminars and workshops. NASTRO 


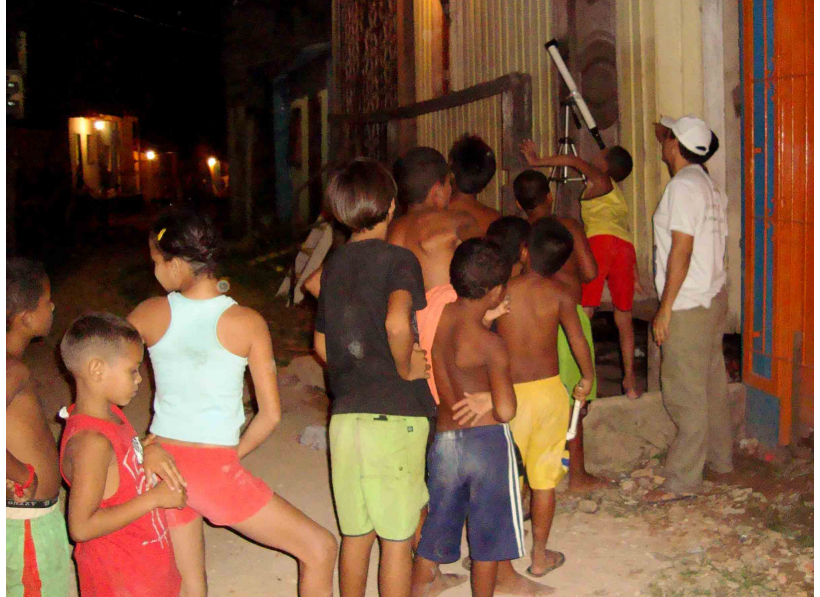

Figure 3: Children in line to observe the Moon through a telescope for the first time in their lives, during a NASTRO's outreach activity promoted in 2011, in a periphery of the city of Belém.

explores Astronomy, Astronautics and related subjects, specially through a playful, interactive and multidisciplinary approach.

The audience of NASTRO includes teachers, students and the society in general, depending on the activity performed. For instance, the astronomical presentations performed with experiments are usually targeted for basic, middle and high school students, while the astronomical observations and seminars are targeted to the general audience. Among the activities promoted by NASTRO at the Belém UFPA campus, stands out the "Astronomical Wednesdays", consisting of seminars about Astronomy, Astronautics, Astrophysics, Cosmology and other related subjects, occurring every Wednesday evening, followed by astronomical observations with different kinds of telescopes (cf. Fig. 6s - supplemental files).

NASTRO contributes to the explanation to the Amazonian society of several phenomena related to Astronomy and Astronautics. As peculiar occurrences, we can mention the finding of rocket parts in the state of Pará, nearby the city of Salinópolis, on April 25, 2014 [13 (cf. Fig. 7s - supplemental files), and in the surroundings of the city of Curuçá, on May 17, 2015 [14. After contacting international space agencies, NASTRO's team realized that these were rocket debris connected to the launching of satellites from Guiana Space Centre in Kourou, French Guiana, that probably fell in the Atlantic ocean and then floated inland. Moreover, almost every year NASTRO's team explains to the local media about tidal effects which, together with the high rate of rainfall, usually happens during the months of March and April, causing flooding in the Guajará bay shore, in the city of Belém, influencing directly the life of people who live and work at that zone 15 .

Regarding solar and lunar eclipses, meteor showers, internal planet transits by the solar disk, and other typical astronomical phenomena, NASTRO offers to the Amazonian population the opportunity of safe and enjoyable observations in public places.

On September 27, 2015 there was an interesting combination of two astronomical events - a lunar eclipse and a "supermoon" - visible in part of Brazil, including Belém, when many people met at Forte do Castelo to observe the two phenomena (cf. Fig. 8s - supplemental files), For that occasion, NASTRO brought several telescopes through which more than a thousand people observed the Moon all night long.

On May 9, 2016 the transit of Mercury across the Sun's disk was visible from the Earth, including the Amazonia, attracting the attention of a considerable number of people. The observation of Mercury's transit was performed by NASTRO at a famous touristic point of Belém, the Ver-o-Peso market, for roughly 7 hours, during which about five hundred people observed the phenomenon (cf. Fig. 4 ).

Along the last decade, in addition to the internal and external activities, NASTRO has also organized and taken part in several events related to Astronomy and science in general. For instance, together with Brazilian National Observatory (ON, http://www.on.br), NASTRO has organized in 2008 the First Amazonian School on Astronomy, Astrophysics and Cosmology. With Brazilian National Institute for Space Research (INPE, http: //www.inpe.br), NASTRO has organized the First (cf. Fig. 9s - supplemental files) and Second (cf. Fig. 10s -

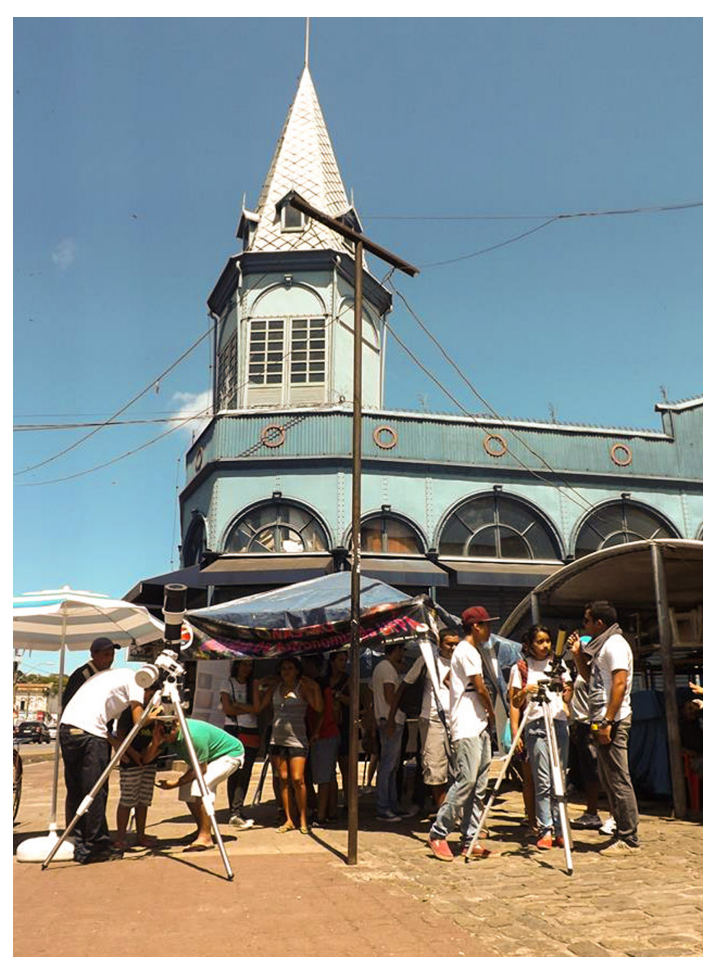

Figure 4: Telescopes mounted in front of the Ver-o-Peso market, to observe planet Mercury's transit in front of the solar disk, on May 9, 2016. 
supplemental files) Amazonian School on Space Sciences, in 2007 and 2008, respectively.

In collaboration with the Pará State Secretariat for Science, Technology and Innovation, together with other scientific, environmental and educational initiatives, NASTRO has participated in itinerant exhibitions in about 30 cities in the Amazonian region (cf. Fig. 5), as well as in islands (cf. Fig. 6- see also Fig. 11s - supplemental files) located in the North-Brazilian coast.

With its outreach and teaching activities, since its foundation, NASTRO has reached more than a hundred thousand people. From this number, more than ninety thousand people were attended outside UFPA, in events promoted in public parks and schools, touristic points, convention centers and universities. NASTRO also became an environment for science teaching research, specifically in Astronomy. Since 2004, about 70 students from different undergraduate courses (including Physics, Chemistry, Biology, Natural Sciences, Meteorology and Philosophy) of UFPA, have represented NASTRO in

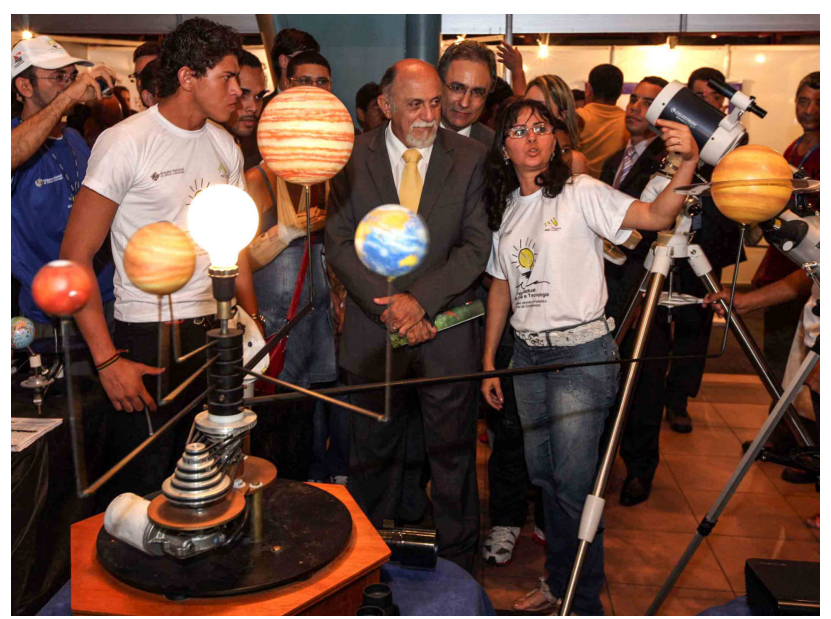

Figure 5: NASTRO's exhibition during the Brazilian Week of Science and Technology, in Belém, in October 2011. In this picture we can see the NASTRO's team and equipment, as well as, among the visitors, the Governor and the Secretary for Science and Technology of the Pará state at the time.

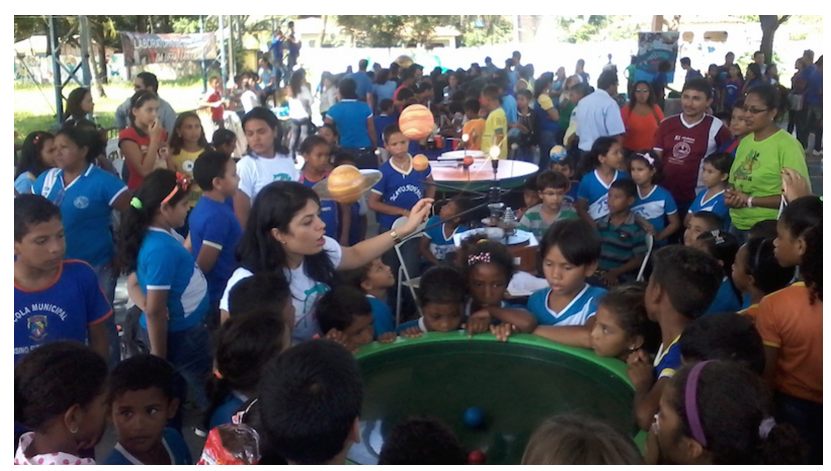

Figure 6: NASTRO's exhibition in the city of Salvaterra, located in the Marajó Island, during Horácio Schneider science and culture fair, in April, 2014. meetings and conferences. More than 200 talks, seminars and workshops have already been offered by NASTRO's team, with an audience adding up to more than six thousand people of different education levels.

NASTRO also prepares Amazonian students for the Brazilian Olympiad of Astronomy and Astronautics and to a national competition of low cost material rockets launching, called Brazilian Exhibition of Rockets. Further details of NASTRO's participation in these two national competitions are mentioned in Sec. 4

The implementation of games and other playful activities in teaching and learning is something very common in children's education. The spontaneity in students' participation, increasing their self-confidence and self-esteem, is frequently seen during these activities. Furthermore, team work of the students and healthy competition atmosphere naturally arise.

Among the experiments and games developed by the collaborators of NASTRO, we can mention the Constellations Memory Game (cf. Fig. 12s - supplemental files) and the Sky Hopscotch [16] (cf. Fig. 13s - supplemental files). These games and other activities promote intense interactive learning atmospheres, normally filled with interesting discussions, improving the understanding of concepts and ideas (cf., e. g., Refs. [17] and [18]), and are widely applied in science centers all over the world.

Among the other activities offered by NASTRO, we can mention workshops in which it is taught how to operate simple telescopes, as well as workshops for telescope making [19 with the use of low cost materials, like paperboard, PVC pipes, and low cost lenses [20] (cf. Fig. 14 s - supplemental files).

\section{NASTRO's Participation in the Brazilian Olympiad of Astronomy and Astronautics and in the Brazilian Exhibition of Rockets}

The Brazilian Olympiad of Astronomy and Astronautics (OBA, http://www.oba.org.br) is a national annual event for primary, middle and high school students, organized by the Brazilian Astronomical Society (SAB, http://www.sab-astro.org.br) and the Brazilian Spatial Agency (AEB, http://www.aeb.gov.br). The OBA demands general knowledge on Astronomy and Astronautics, in different degrees of difficulty, grouped in four levels. Level 1 of the OBA is devoted to primary-school students of the first years; level 2 is devoted to primaryschool students of the last years; level 3 is devoted to middle-school students; and level 4 is devoted to highschool students. NASTRO provides classes conducted by its collaborators, aiming to prepare the students from Pará state schools who want to participate in the OBA, serving especially students in the neighborhood of the Belém UFPA's campus (cf. Fig. 7- see also Figs. 15s and $16 \mathrm{~s}$ - supplemental files). 


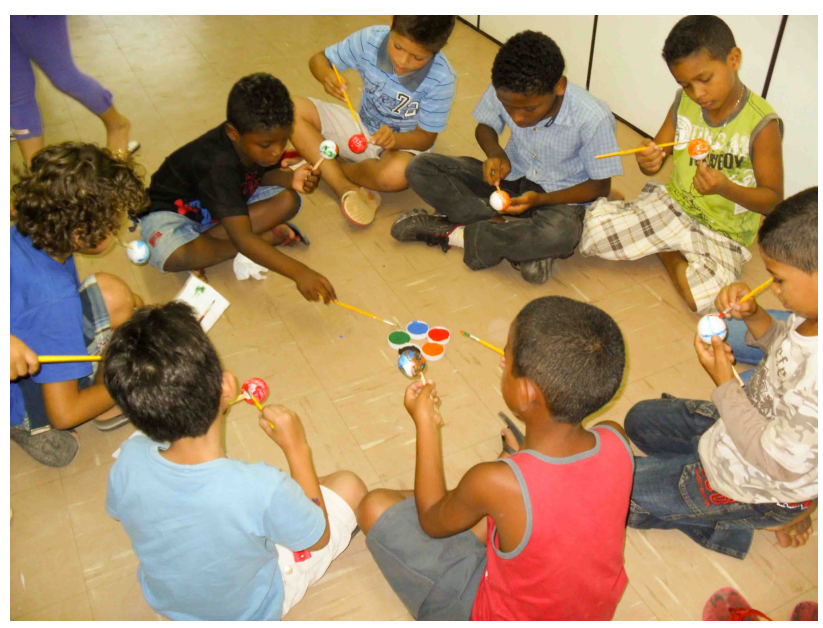

Figure 7: NASTRO's students painting during a class, aiming to build a solar system model, in 2012 .

The methodological approach applied in preparatory classes include educational games (cf., e. g., Refs. 16 21, 22 ), audiovisual resources, interactive equipment, apart from astronomical observations. These classes are taught every week on Saturday mornings. The students from the first three OBA levels usually come accompanied with their parents or relatives, who are invited to participate and also enjoy the activities. A student's mother reported with enthusiasm her participation in these activities 23$]$ : "I come with her every Saturday and I stay to attend the classes. (...) It is very interesting (...). I myself learn a lot too. I am loving it. (...) I intend to keep on coming". And complemented: "Even if my daughter stops coming, I intend to come alone (...)". (A statement followed by a spontaneous and extended laugh.) This kind of testimony encourages even more the development of diffusion and popularization of science activities on Astronomy by NASTRO's team, for children, teenagers, as well as for adults.

The OBA classes started in UFPA in 2005, remaining until today totally free of charge, as it has been the case of all NASTRO's activities. Even when NASTRO's students do not get grades high enough to obtain OBA's national awards (usually accompanied by symbolic plastic medals), a local award ceremony (cf. Fig. 17s - supplemental files) is organized for all the NASTRO's participants of the competition.

Another national competition promoted by SAB and AEB is the Brazilian Exhibition of Rockets (MOBFOG). This competition's goal is to launch handmade rockets to obtain a large horizontal range. According to the MOBFOG rules, there are four types of rockets that can be used in the launches, some of them specific for the higher levels. In levels 1 and 2 the students can build rockets with soda straws and paper tubes, respectively. In levels 3 and 4 students can build rockets using polyethylene terephthalate (PET) bottles. For levels 1 and 2, the rockets are launched with water and air pressure propulsion, and for levels 3 and 4 sodium bicarbonate and vinegar can be used in the propulsion mixture.

NASTRO's students also participate in the MOBFOG. The rockets construction is supervised by NASTRO's collaborators (cf. Fig. 8) and the rockets launching is always an activity highly enjoyed by all participants (cf. Fig. 91. NASTRO also organizes a local award ceremony for students who obtain the larger horizontal range with their rockets, independently of their positions in the national awards raking.

NASTRO has directly enrolled a total of around one thousand students in these OBA and MOBFOG preparatory activities, from fundamental, middle and high school levels, with an annual average of 100 subscriptions.

\section{Other Astronomy Centers and Groups in the Brazilian Amazonia}

Besides NASTRO, other initiatives on diffusion and popularization of Astronomy have been realized in the Brazil-

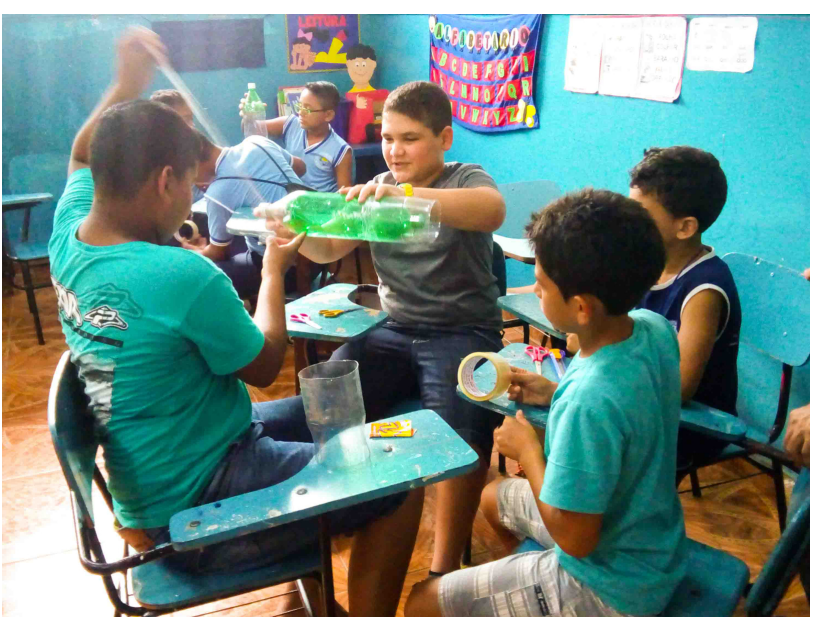

Figure 8: Low cost material rockets' construction during a Science and Technology Fair in the city of Igarapé-Miri (FEICITI), in November 2015.

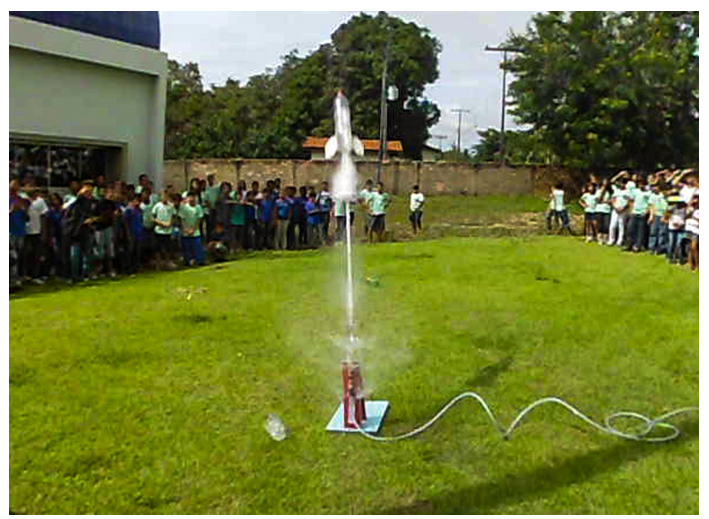

Figure 9: A rocket's launch done by NASTRO's team in Camilo Vianna science exhibition, in IFPA, in the city of Conceição do Araguaia, in March 2012. 
ian Amazonia. Among them, there are amateur clubs, societies, centers and planetariums, dedicated to education and public outreach. In this section, we present a selection of those initiatives.

Amateur clubs and astronomical societies are usually the mostly adopted alternatives to supply the lack of specific centers for teaching and popularization of Astronomy in the Amazonian region. They emerge, in many cases, from meetings of teachers and students interested in astronomical and cosmological issues, and, in most of the cases, these teachers do not have a formal education on Astronomy, and are sometimes initially stimulated by the intense dissemination of movies, television series, etc., increasingly accessible to the general public.

In the Brazilian Amazonia, besides the curiosity eventually stimulated by the media, the cultural diversity found in the indian ancestry of part of the population provides additional motivation for astronomical issues. The proposal to comprehend how the old Amazonian indian tribes explain stars, its movements in the sky and the phenomena associated to them, are relevant issues in Ethnoastronomy.

Groups gathered by Astronomy interests sometimes turn into mature initiatives, as the case of the Maranhão Astronomy Society (SAMA, http://sama-astronomia. blogspot.com.br). Having started their meetings in December 1976, the SAMA group works in public activities of scientific outreach, including seminars and astronomical observations in the city of São Luís, capital of the Maranhão state. Inspired on this initiative, other groups were formed, like the Amateur Group on Astronomy of Imperatriz, inland city of Maranhão state, associated with Federal Institute of Maranhão (IFMA, http:// ifma.edu.br). Still in Maranhão's state, we can also mention the Group of Astronomical Studies (GEAST, http: //geast-uema.blogspot.com.br) of the State University of Maranhão (UEMA, http://www . uema.br), that met for the first time in April 2008. Counting with the participation of students and professors of Physics Graduation Course, besides founders of SAMA, GEAST/UEMA also collaborated towards the creation of the Physics Astronomical Observatory (OBAFIS) of UEMA, on December 2008. OBAFIS aims to promote knowledge in Astronomy through observations, seminars and other activities offered to the general public.

Other amateur groups devoted to Astronomy emerged in the beginning of the twenty first century in the Brazilian Amazonia. For instance, we can mention: (i) Gama Hidra Astronomy Group, in the Acre state (Gama Hidra, http://www.gamahidra.com.br); (ii) Mirzam Astronomy Club of Macapá (Mirzam, http://clubemirzam. blogspot.com.br), in the Amapá state; (iii) Stride Astronomy Club (Stride, http://astronomia-stride. blogspot.com.br), associated with Federal Institute of Rondônia (IFRO, http://ifro.edu.br), in the Rondônia state; (iv) Astronomy Club of Pará (CAP, http://astropara.wordpress.com), in the Pará state; among others. We can also mention other groups created recently, like the Astronomy Club of Primavera do Norte, inland city of the Mato Grosso state; the Astronomy Club of Manaus, in the Amazonas state; and Galileo Academic League of Astronomy, in Bragança, in the Pará state. There are also groups which have been founded by teachers of institutions of higher education, like the Nucleus for Teaching and Research in Astronomy (NEPA) [24], in the Amazonas state, associated with State University of Amazonas (UEA, http://www.uea.edu.br), and the Astronomy Center of the Federal Institute of Pará (IFPA, http://www.ifpa.edu.br), in the Pará state.

Due to the continuous enhancement of educational actions in Astronomy, the number of programs and projects encouraging activities in scholar and public environments is increasing in Amazonia. The itinerant GalileoMobile Project (Galileo Mobile, http://www.galileo-mobile. org) is one of these programs aiming to inspire the scientific curiosity, the critical though and citizenship in the Amazonian region. With collaborators all around the world, besides counting the partnership of amateur groups, as the Gama Hidra, as well as professors and students of IFRO, the GalileoMobile organized the BraBo expedition in Acre and Rondônia states. The activities in this expedition included seminars, workshops and astronomical observations in schools and parks, with a total public of more than 3500 people along the $1600 \mathrm{~km}$ covered during 5 weeks. This itinerant initiative, mobilized elementary, secondary, technical and high-school students, besides specific activities offered for visually impaired individuals, and also provided an opportunity for cultural exchange with indian students, as reported in the documentary entitled Ano-Luz 25].

Poor weather conditions impose a strong difficulty to astronomical observations in Amazonia. Due to its location in an equatorial environment, characterized by a hot and humid weather, with extensive and intensive rainy periods, sometimes it is simply impossible to perform astronomical observations with optical instruments in Amazonia for several days. Moreover, telescopes are negatively influenced by the high relative humidity, of about $90 \%$ in rainy periods. A way to minimize the frustration of a cancelled astronomical observation due to poor weather conditions is the use of computer softwares, projecting to people the sky hidden behind the clouds, as well as mobile planetariums.

The first planetarium located in the Brazilian Amazonia was founded in September, 1999, in the city of Belém, Pará state capital, motivated by an annular solar eclipse that occurred in April, 1995, which could be fully visible from Belém. The Pará State Planetarium, was originally named Sebastião Sodré da Gama, in honor to the Pará state scientist and director of National Observatory of Rio de Janeiro from 1930 to 1950 [26]. This Amazonian planetarium belongs to the State University of Pará (UEPA, http://www.uepa.br). With the main goal to collaborate with the improvement of science teaching 
in the Amazonian region, it is claimed to be one of the first world planetariums that presents a multidisciplinary propose involving both astronomical and environmental sciences [27]. The Pará State Planetarium is equipped with a Skymaster ZKP-3 projector, which shows constellations, planets, comets, among other astronomical objects.

Some private entities, as the Brazilian Commerce Social Service (SESC), and public sectors, as the State Secretariats for Science, Technology and Innovation, promote actions with portable planetariums performing itinerant exhibitions in the Brazilian Amazonia, specially devoted to municipalities which do not have science centers [28]. As an example of portable planetarium operating in the Brazilian Amazonia, we can mention the Maywaka Planetarium of the Institute for Scientific and Technological Research of the Brazilian state of Amapá (IEPA, http://www .iepa.ap.gov.br). The word Maywaka means "Universe" in the arawak language of the indian community Palikur, old inhabitants of the upper margin of the Amazon river. Maywaka is an Aster IV, Asterdomus planetarium, with a dome of about 5 metres in diameter. The Maywaka Planetarium has started its activities in 2002, and since then it has conducted public sessions for hundreds of Amapá state citizens. Nowadays, the Maywaka Planetarium performs activities in the Sacaca Museum of Amapá state. As an example of a museum that develops activities on Astronomy and Ethnoastronomy, we can mention the Amazonia Museum (MUSA, http://museudaamazonia.org.br), located in the city of Manaus, in the Amazonas state. Founded in 2009, the MUSA promotes seminars, workshops and other environmental education projects, in support of scientific research and outreach. MUSA also hosts an "indian planetarium" built with the goal of showing how Amazonian indian groups used to interpret Astronomy.

The existence of such initiatives in the Brazilian Amazonia is essential for the improvement of teaching quality in Brazil as a whole. It should be noticed that the majority of the cities in the Brazilian Amazonia possesses the least Human Development Index of the country. Although the enhancement of this index is clearly a complex issue, demanding more than simply several governmental actions, the support given by educational and outreach initiatives is essential for the gradual advance towards positive future perspectives for one of the richer regions of our planet, in terms of biodiversity and culture.

\section{Final Remarks}

As one of the most ancient sciences, Astronomy is related to human development, helping humankind to understand several phenomena of the Universe in which it is inserted, including the seasons, what contributed to the advancement of agriculture, tidal effects and eclipses.

Despite the popularization of scientific knowledge and the efforts for the demystification of astronomical phe- nomena in the Brazilian Amazonia, some stories and tales, inherited from the Amazonian indian native tribes, that developed their own ways to interpret the behavior of celestial bodies, are still present in the local culture. Legends and myths, some associated to constellations' denominations in Amazonian indian languages, still compose the social imaginary of the Amazonian population.

It is difficult to describe the fascination which arises when a person looks at celestial objects through a telescope for the first time. The first view of the lunar craters, Saturn rings, Galilean moons of Jupiter, dozens of stars of an agglomerate, or a whole galaxy in the visual field of an eyepiece is something remarkable.

Nowadays, astronomical phenomena are usually predicted with great anticipation and high accuracy, which, together with astronautical achievements, are widely spread through communication channels, motivating numerous questions from the the general public. Such questions involve different subjects, including, for instance, the movements of the Sun, Moon, planets, stars, galaxies, and the Universe as a whole; as well as more elaborated and subtle issues, like the possibility of building space colonies, essential to guarantee humankind survival in case the Earth becomes an uninhabitable planet, and the existence of intelligent life in other places of the Cosmos. Despite the enormous technological advance of our civilization, part of the global population still does not have access to scientific information, and the change of this situation through a process of diffusion and popularization of science and technology is essential to establish a global developed society.

We have reported educational and public outreach activities performed in the Brazilian Amazonia on Astronomy and Astronautics, giving special emphasis to the Astronomy Nucleus (NASTRO) at Federal University of Pará (UFPA), which has celebrated ten years of existence in 2016, attending more than a hundred thousand people since its foundation, helping to spread scientific knowledge in Amazonia. We have also presented a selection of science centers and groups dedicated to Astronomy outreach in the Brazilian Amazonia.

Even facing rainforest's high humidity, normally causing unstable meteorological conditions, together with cloudy sky and rainfall, NASTRO has successfully promoted, along more than one decade, the diffusion and popularization of Astronomy and Astronautics, enhancing scientific knowledge and interest of the Brazilian Amazonia population.

Initiatives like NASTRO stimulate research, not only in science teaching and outreach, but also in other areas, like, for instance, history and philosophy of science [29]. More than 30 academic works have been produced by NASTRO's team, including undergraduate monographs (cf., e. g., 30-33]), as well as works presented in Brazilian conferences (cf., e. g., $34-37$ ). These academic works usually explore the methodological approach and the impact of Astronomy education and public outreach in 
the Brazilian Amazonia, also aiming to explain to the general audience about astronomical phenomena.

Stimulating scientific development in the Brazilian Amazonia demands a series of systematic actions and support. The higher the scientific literacy degree is, the higher is the population awareness about the environmental phenomena and the main troubles which involve the human influence on nature. The maturation of citizenship ideals in Amazonia is required as a way to educate young people for the future, as well as to preserve the Amazonian forest, where a great biodiversity of our planet is kept.

\section{Acknowledgements}

We thank Ariana D. Nascimento, Augusto C. M. Chaves, Brenda B. Moreira, Carlos E. P. Martins, Elisangela B. Santana, Franciney C. Palheta, Francilene C. Costa, Girlan E. N. de Souza, Gleyce S. da R. Oliveira, Igor J. C. Coimbra, Jerry W. L. Alves, Jessica P. Estácio, Jorge C. Rodríguez, Laisse C. Ramos, Lizangela M. A. da Silva, Maiara F. da S. Cardoso, Marcio G. dos Santos, Maria I. A. da Silva, Sabrina F. da Costa, Wilson de C. A. Silva and Ygor P. Silva, for their special dedication to the Astronomy Nucleus (NASTRO) of the Federal University of Pará. We are also grateful to the whole NASTRO's team for collaboration and work. We acknowledge our gratitude also to Aníbal F. de Figueiredo Neto and Ildeu de C. Moreira. We are grateful to Rosa E. C. C. Lopes and Ângela B. Klautau for useful comments. We acknowledge the support of the Physics Faculty of the Institute of Exact and Natural Sciences, the Institute of Geosciences, and the Outreach Sector of Federal University of Pará (UFPA). We would like also to thank Ministry of Science, Technology, Innovations and Communications (MCTIC), Conselho Nacional de Desenvolvimento Científico e Tecnológico (CNPq), and Financiadora de Estudos e Projetos (FINEP), from Brazil, for partial financial support.

\section{Supplementary material}

The following online material is available for this article: Supplementary Figures

\section{References}

[1] G.L. Cameron, Public Skies: Telescopes and the Popularization of astronomy in the twentieth century. Graduate Dissertation, Iowa State University, Paper 11795, 2010.

[2] J. Rosendhal, P. Sakimoto, R. Pertzborn and L. Cooper, Advances in Space Research 34, 2127 (2004).

[3] T.G. Guzik, E. Babin, W. Cooney, J. Giammanco, D. Hartman, R. McNeil, M. Slovaka and J.G. Stacy, Advances in Space Research 34, 2121 (2004).

[4] J. Saucedo-Morales and P. Loera-González, Journal of Advanced Research 4, 315 (2013).

[5] M. Boër, Advances in Space Research 42, 1831 (2008).
[6] Instituto Brasileiro de Geografia e Estatística, Atlas do Censo Demográfico 2010, available from http:// censo2010.ibge.gov.br/apps/atlas

[7] L.C.B. Crispino, V.B. Bastos e P.M. Toledo (orgs), As Origens do Museu Paraense Emílio Goeldi. Aspectos Históricos e Iconográficos (1860-1921) (Paka-tatu, Belém, 2006).

[8] Diário de Notícias, O cometa (Belém, 5th October, 1882).

[9] M.C. Lima and L.C.B. Crispino, International Journal of Modern Physics D 25, 1641002 (2016).

[10] L.C.B. Crispino and M.C. Lima, Phys. Perspect. 18, 379 (2016).

[11] L.C.B. Crispino e M.C. Lima, Revista Brasileira de Ensino de Física 38, e4203 (2016).

[12] J. Caldas e L.C.B. Crispino, Revista Brasileira de Ensino de Física 39, e2309 (2017).

[13] G1, Moradores Encontram Objeto Não Identificado em Vila de Salinas/PA, (G1 Pará, Belém, 29 abr. 2014), available from g1.globo.com/pa/para/noticia/2014/ 04/moradores-encontram-objeto-nao-identificadoem-vila-de-salinas-pa.html

[14] ORM NEWS, Lixo Espacial é Encontrado em Curuçá, Nordeste Paraense (ORM NEWS, Belém, 20 mai 2015), available from http: //www . ormnews.com.br/noticia/lixo-espaciale-encontrado-em-curuca-nordeste-paraense.

[15] G.M.G. Souza, R.R. França, F.C. Palheta e L.C.B. Crispino, in: XVIII Jornada de Extensão Universitária, Belém, 2015, available from http://proex.ufpa.br/XVIII_jornada_anais/-/ docs/educacao/oral/75.pdf

[16] L.C.B. Crispino, L.M.A. Silva e B.B. Moreira, in: $58^{a}$ Reunião Anual da Sociedade Brasileira para o Progresso da Ciência, Florianópolis, 2006, available from http://www.sbpcnet.org.br/livro/58ra/ SENIOR/RESUMOS/resumo_3390.html/

[17] E.E. Prather, A.L. Rudolph and G. Brissenden, Physics Today 62, 41 (2009).

[18] M.M. Montgomery, The Physics Teacher 44, 607 (2006).

[19] N.E. Howard, Standard Handbook for Telescope Making (Harper \& Row, Publishers, New York, 1984).

[20] S.F. Tonkin (ed), Amateur Telescope Making (SpringerVerlag Limited, London, 1999).

[21] E.B. Santana, M.A. Santos e F.C. Palheta, in: 15ํㅡ Encontro Nacional de Astronomia, São Luís, 2012, available from http://enast2012.blogspot.com.br.

[22] E.B. Santana, B.F.N. Castro e F.C. Palheta, in: $15^{\circ}$ Encontro Nacional de Astronomia, São Luís , 2012, available from http://enast2012.blogspot.com.br.

[23] Rádio Web UFPA, Celebration of NASTRO's Tenth Anniversary, available from http://radio.ufpa.br/ novaradio/index.php/acervo-do-ufpa-ensino

[24] Governo do Estado do Amazonas, Pesquisas Desenvolvidas em Parintins Destacam Novas Metodologias para o Ensino da Astronomia (Governo do Estado do Amazonas, Manaus, 2013), available from http: //www . amazonas.am.gov.br/2013/09/pesquisasdesenvolvidas-em-parintins-destacam-novasmetodologias-para-o-ensino-da-astronomiaurl

[25] Felipe Carrelli, Ano-Luz, available from https://vimeo. com/121350155 
[26] L.M. Barreto, Observatório Nacional - 160 Anos de História (Observatório Nacional/Academia Brasileira de Ciências, Rio de Janeiro, 1987).

[27] M. Sauma Filho, Astronomy Brasil 15, 74 (2007).

[28] Projeto SescCiência, available from http: //www.sesc.com.br/portal/educacao/Educacao_ Complementar/Sesciencia

[29] J. Caldas, M.C. Lima e L.C.B. Crispino, Revista Brasileira de Ensino de Física 38, e4307 (2016).

[30] G.S.R. Oliveira, Ensino de Ciências Por Meio da Astronomia: O Estudo do Sol como Atividade Motivadora para Conceitos de Física do $9^{o}$ Ano. Undergraduate Course Monograph, Federal University of Pará, 2015.

[31] L.C. Ramos, O Núcleo de Astronomia da UFPA: Um Pólo de Difusão e Popularização da Astronomia no Pará. Undergraduate Course Monograph, Federal University of Pará, 2009.

[32] L.M.A. Silva, Práticas Atuais de Astronomia em Belém do Pará: Planetário do Pará, Núcleo de Astronomia da UFPA e Outras Iniciativas. Undergraduate Course Monograph, Federal University of Pará, 2007.

[33] M.I.A. Silva, A Importância das Mostras de Ciência e Cultura para a Divulgacão e Popularizacao Científica no Estado do Pará: As Vivências de uma Professora em Formação. Undergraduate Course Monograph, Federal University of Pará, 2014.

[34] E.P. Ribeiro, E.B. Santana e F.C. Palheta, in: 15ํ Encontro Nacional de Astronomia, São Luís, 2012, available from http://enast2012.blogspot.com.br

[35] E.B. Santana e F.C. Palheta, in: $14^{\circ}$ Encontro Nacional de Astronomia, São Paulo, 2011, available from http://www.14.enast.com.br/programacaofinal-14-enast.pdf

[36] L.M.A. Silva, F.C. Costa e L.C.B. Crispino, in: $12^{\underline{a}}$ Encontro Nacional de Astronomia, Londrina, 2009, available from http://web.sercomtel.com.br/enast.

[37] Y.P. Silva, L.C.B. Crispino e F.C. Palheta, in: $6^{o}$ Congresso Brasileiro de Extensão Universitária, Belém, 2014, available from http://www. $6 \mathrm{cbeu}$.ufpa.br/ebook 